\title{
Limited Effect of Intravenously Administered Indoxyl Sulfate, a Uremic Toxin, on the Hepatic Transport of Pravastatin in Normal Rats
}

\author{
Hideyuki Suga, Yuichi Ichimura, Satomi Otsuka, Kaori Sugaya, \\ Masako Oda, Hiroshi Saitoh* \\ Department of Pharmaceutics, School of Pharmaceutical Sciences, Health Sciences University of Hokkaido, \\ Ishikari-Tobetsu, Japan \\ Email: *saitoh@hoku-iryo-u.ac.jp
}

How to cite this paper: Suga, H., Ichimura, Y., Otsuka, S., Sugaya, K., Oda, M. and Saitoh, H. (2018) Limited Effect of Intravenously Administered Indoxyl Sulfate, a Uremic Toxin, on the Hepatic Transport of Pravastatin in Normal Rats. Pharmacology \& Pharmacy, 9, 270-278.

https://doi.org/10.4236/pp.2018.97021

Received: May 24, 2018

Accepted: July 24, 2018

Published: July 27, 2018

Copyright $\odot 2018$ by authors and Scientific Research Publishing Inc. This work is licensed under the Creative Commons Attribution International License (CC BY 4.0).

http://creativecommons.org/licenses/by/4.0/ Open Access

\begin{abstract}
Indoxyl sulfate (IS) is a typical uremic toxin that extensively accumulates in the plasma of patients with seriously impaired renal function. This study seeks to clarify whether IS exerts a potent modulating effect on the hepatic transport of pravastatin, which is a substrate of both organic anion transporting peptides (OATPs) and multidrug resistance-associated protein (Mrp) 2 in rats. When IS is administered intravenously to the normal rats at a dose of 120 $\mu \mathrm{mol} / \mathrm{kg}$; plasma IS levels are approximately $600 \mu \mathrm{M}$ after $2 \mathrm{~min}$ and $100 \mu \mathrm{M}$ after $120 \mathrm{~min}$. In rats with acute renal failure (ARF) induced by cisplatin, the area under the curve (AUC) was more than 2.5-fold greater compared with that in the normal rats, indicating that IS accumulates in ARF rats. Intravenously administered pravastatin almost disappeared from the plasma by 60 min post-administration and approximately $55 \%$ of dose was excreted in the bile within $60 \mathrm{~min}$. This result suggested that pravastatin was efficiently taken up from the sinusoid into hepatocytes via rat OATPs on the sinusoidal membrane and preferentially transported in the bile mediated by Mrp2 on the canalicular membrane. IS administered intravenously at a dose of $120 \mu \mathrm{mol} / \mathrm{kg}$ caused neither an increase in plasma pravastatin levels nor a decrease in its biliary excretion. In conclusion, the present results demonstrate that single intravenous administration of IS does not interfere with the hepatic transport of pravastatin directly in vivo, which is at variance with the results of previous in vitro studies.
\end{abstract}

\section{Keywords}

Indoxyl Sulfate, Pravastatin, Drug Interaction, Hepatic Transport, Biliary Excretion 


\section{Introduction}

It is generally understood that under seriously impaired renal function a variety of uremic toxins accumulate in the body at greater plasma levels, with indoxyl sulfate (IS) typical of such uremic toxins [1]. Elevated IS levels leads to the induction of various unfavorable events such as progression to renal failure, and cardiovascular and bone toxicities [2] [3]. IS accumulation is attributed primarily to the fact that IS is a potent substrate of organic anion transporter (OAT) and OAT3 presents on the basal membrane of the renal epithelial cells [4] [5]. It was reported previously that, after intravenous administration, IS was eliminated from the rat plasma much faster than other anionic uremic compounds, such as hippuric acid, 3-carboxy-4-methyl-5-propyl-2-furanopropanoic acid, and indole-3-acetic acid [6], implying a greater involvement of OATs in the elimination of IS via the renal secretory system. Moreover, IS is a highly protein-bound compound. Based on these characteristics, IS is considered to be associated with the occurrence of clinically relevant pharmacokinetic drug interactions in the patients with impaired renal function.

There has been a good deal of interest in the alteration of nonrenal drug clearance in patients with severe chronic kidney disease (CKD) [7]. In this context, the modulating effects of uremic toxins on drug metabolism and transport have been emphasized [8] [9]. To date, several in vitro studies have suggested that IS possesses the ability to directly inhibit organic anion transporting polypeptides (OATPs) [10] [11] [12], which localize on the sinusoidal membrane of hepatocytes. It was also reported that IS is transported by OATP1B3, not by OATP1B1 [13]. However, little information is currently available on whether IS exerts its modulating effect on the hepatic OATP-mediated transport in vivo. It is well known that OATP1B1, OATP1B3, and OATP2B1 are involved in the transfer of statins from the sinusoid into hepatocytes, where statins exert their pharmacological actions [14]. On the other hand, it is known that the adverse events, such as myopathy and rhabdomyolysis, induced by statins occur preferentially in the patients with seriously impaired renal function. If IS directly interferes with OATP-mediated statin transport in such patients, it is likely that elevated IS levels in patient plasma are responsible for the adverse events induced by statins. In order to assess this, we investigated whether intravenously administered IS can modulate the hepatic transport of pravastatin in normal rats in vivo.

\section{Materials and Methods}

\subsection{Materials}

IS and pravastatin sodium were purchased from Sigma-Aldrich (St. Louis, MO, USA). Cisplatin was obtained from Nichi-Iko Pharm. Co. (Toyama, Japan). All other regents were of the highest grade available.

\subsection{Administration of IS and Pravastatin to Rats}

In this study, principles of good laboratory animal care were followed and ani- 
mal experimentation was performed in compliance with the Guidelines for the Care and Use of Laboratory Animals in the Health Sciences University of Hokkaido.

IS was dissolved in saline at a concentration of $11.5 \mathrm{mM}$ or $60 \mathrm{mM}$, and pravastatin was dissolved in a mixture of polyethylene glycol 400 and saline (1:1) at a concentration of $1 \mathrm{mM}$. Following cannulation with a polyethylene tube into the bile duct, IS and pravastatin were administered into jugular vein. The doses of IS administered were $23 \mu \mathrm{mol} / \mathrm{kg}$ or $120 \mu \mathrm{mol} / \mathrm{kg}$, and that of pravastatin was 2 $\mu \mathrm{mol} / \mathrm{kg}$. In this experiment, IS was administered $5 \mathrm{~min}$ prior to pravastatin administration. Two doses of IS were based on our preliminary studywhich investigated IS levels in CKD and hemodialysis patients. Blood $(0.4 \mathrm{~mL})$ was drawn at 2, $5,1020,30$, and $60 \mathrm{~min}$ after administration and plasma samples were kept at $-30^{\circ} \mathrm{C}$ until assay. The bile was collected at 30 -minute intervals. ARF rats were induced by the intraperitoneal administration of cisplatin $(5 \mathrm{mg} / \mathrm{kg})$ and used after 3 days following confirmation of elevated serum creatinine levels.

\subsection{HPLC Analysis}

After deproteinization with methanol, IS and pravastatin levels in the plasma were assayed using a Shimadzu LC-10A HPLC system (Kyoto, Japan) equipped with a Shimadzu SPD-10 UV spectrophotometer. Chromatographic conditions were as follows: column, Cosmosil 5C18-AR (i.d.: $4.6 \mathrm{~mm}$, length: $15 \mathrm{~cm}$, NakalaiTesque Inc., Kyoto, Japan) for IS and Inertsil ODS-3 (i.d.: $4.6 \mathrm{~mm}$, length: 15 $\mathrm{cm}$, GL Science Inc., Tokyo, Japan) for pravastatin; mobile phase, $0.05 \mathrm{M}$ $\mathrm{KH}_{2} \mathrm{PO}_{4} / \mathrm{CH}_{3} \mathrm{OH}$ (9:1) for IS and 7:6 and $2.5 \mathrm{mM} \mathrm{CH}_{3} \mathrm{COONH}_{2} / \mathrm{CH}_{3} \mathrm{CN}(7: 3)$ for pravastatin; wave length, $282 \mathrm{~nm}$ for IS and $238 \mathrm{~nm}$ for pravastatin; column temperature, $40^{\circ} \mathrm{C}$ or $50^{\circ} \mathrm{C}$; flow rate, $1 \mathrm{ml} / \mathrm{min}$; and injection volume, $40 \mu \mathrm{l}$. IS and pravastatin were reproducibly assayed with a coefficient of variance of less than $5 \%$.

\subsection{Data Analysis}

The AUC was calculated using the trapezoidal method. Data are expressed as the mean with SD of 3 to 4 experiments. Statistical analyses were performed using ANOVA, Dunnett test and Student's $t$-test, with $p<0.05$ considered to be significant.

\section{Results}

\subsection{Plasma IS Levels after Intravenous Administration to Normal and Acute Renal Failure (ARF) Rats}

First, we investigated the time course of plasma IS levels after intravenous administration to rats with normal renal function at two doses. At the first sampling time point ( $2 \mathrm{~min}$ ), plasma IS levels were approximately 600 and $200 \mu \mathrm{M}$ after administration at the doses of $23 \mu \mathrm{mol} / \mathrm{kg}$ and $120 \mu \mathrm{mol} / \mathrm{kg}$, respectively (Figure 1(a)). While plasma IS almost completely disappeared after $60 \mathrm{~min}$ at a 


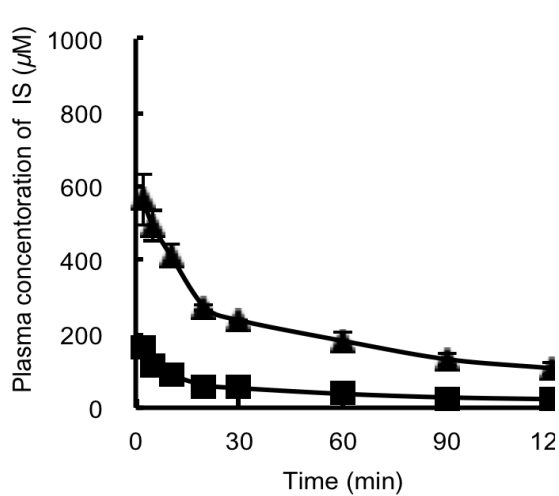

(a)

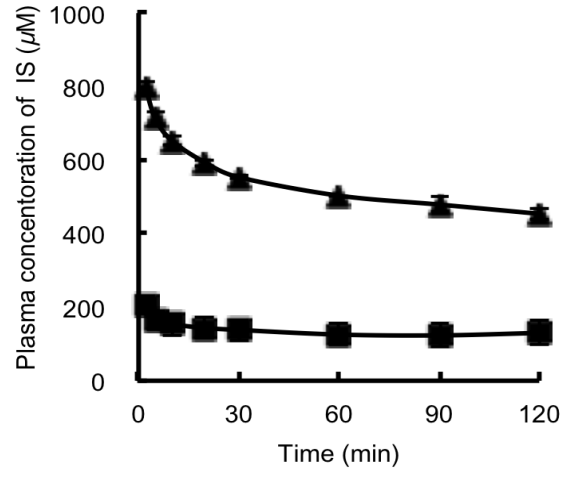

(b)

Figure 1. Time courses of IS after intravenous administration to normal (a) and ARF (b) rats. Each point represents the men with S.D. of 3 to 4 experiments. Closed triangles: at a dose of $23 \mu \mathrm{mol} / \mathrm{kg}$; closed squares: at a dose of $120 \mu \mathrm{mol} / \mathrm{kg}$.

dose of $23 \mu \mathrm{mol} / \mathrm{kg}$, that at a dose of $120 \mu \mathrm{mol} / \mathrm{kg}$ was more than $100 \mu \mathrm{M}$ even at $120 \mathrm{~min}$. When IS was administered to the experimentally induced ARF rats at the same doses, plasma IS levels were much greater compared with those obtained in the normal rats (Figure $1(\mathrm{~b})$ ). $\mathrm{AUC}_{\mathrm{iv}}, 2-120$ min values in ARF rats were approximately 2.9-fold (at a dose of $23 \mu \mathrm{mol} / \mathrm{kg}$ ) and 2.6-fold (at a dose of $120 \mu \mathrm{mol} / \mathrm{kg}$ ) greater than the corresponding values in normal rats (Table 1). The blank plasma IS levels before IS administration were $2.17 \pm 0.12 \mu \mathrm{M}$ in normal and $23.7 \pm 5.1 \mu \mathrm{M}$ in ARF rats. It is well known that plasma IS levels are markedly elevated in severe CKD [15] [16]. The present results suggested the presence of significant IS accumulation even in ARF, possibly due to the lowered activities of the OAT-mediated renal secretory transport.

\subsection{Effect of IS on the Plasma Levels of Pravastatin in Normal Rats}

Next, we evaluated the effect of IS on the clearance of pravastatin from rat plasma after intravenous administration. Pravastatin is partially excreted in the urine after oral administration in humans [17], with OATs known to be involved in the process [18]. Therefore, in this study, we used normal rats in order to exclude the impact of impaired renal function on the elimination of pravastatin. As shown in Figure 2, the plasma levels of pravastatin declined very sharply and became almost negligible after $60 \mathrm{~min}$ in the absence of IS. When IS was introduced into the jugular vein at doses of $23 \mu \mathrm{mol} / \mathrm{kg}$ and $120 \mu \mathrm{mol} / \mathrm{kg}$ (Figure 2), the disappearance of pravastatin in the plasma was slightly, although not significantly, enhanced. $\mathrm{AUC}_{\mathrm{iv}, 2-60 \mathrm{~min}}$ values were $79.9 \pm 25.9 \mu \mathrm{mol} \cdot \mathrm{min} / \mathrm{L}$ (pravastatin alone), $52.0 \pm 1.6 \mu \mathrm{mol} \cdot \mathrm{min} / \mathrm{L}$ (with $23 \mu \mathrm{mol} / \mathrm{kg}$ IS), and $51.8 \pm 5.0 \mu \mathrm{mol} \cdot \mathrm{min} / \mathrm{L}$ (with $120 \mu \mathrm{mol} / \mathrm{kg}$ IS).

\subsection{Effect of IS on the Biliary Excretion of Pravastatin in Normal Rats}

The biliary excretion of pravastatin is shown in Figure 3. When pravastatin was intravenously administered alone, approximately $55 \%$ of the dose appeared in 
Table 1. AUC ${ }_{\mathrm{iv}, 2-120 \text { min }}$ values after the intravenous administration of IS to normal and ARF rats.

\begin{tabular}{ccc}
\hline & \multicolumn{2}{c}{ Dose } \\
\cline { 2 - 3 } & $23 \mu \mathrm{mol} / \mathrm{kg}$ & $120 \mu \mathrm{mol} / \mathrm{kg}$ \\
\hline Normal rats & $5371.8 \pm 410.9$ & $24361.2 \pm 1246.5$ \\
ARF rats & $15724.0 \pm 3416.9$ & $62240.3 \pm 934.9$ \\
\hline
\end{tabular}

The unit for the AUC was $\mu \mathrm{mol} \cdot \mathrm{min} / \mathrm{ml}$.

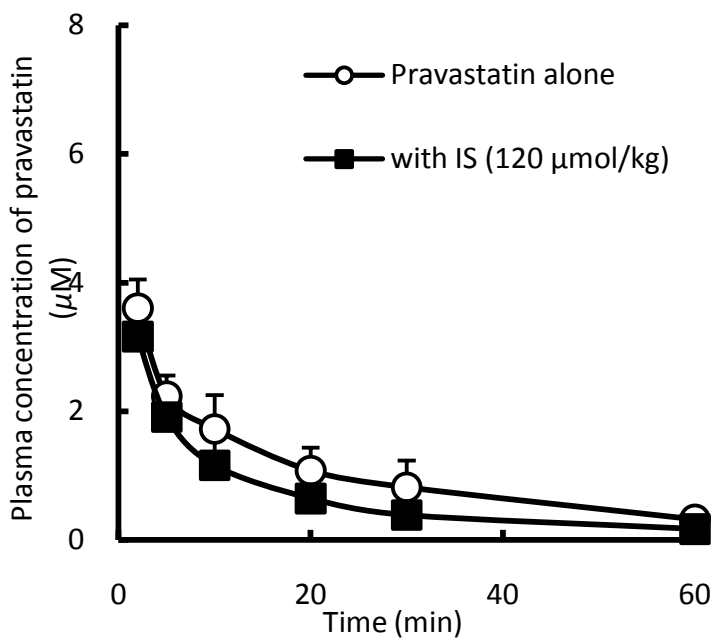

Figure 2. Effects of the intravenous administration of IS on the plasma levels of pravastatin. Each point represents the mean with S.D. of 3 to 4 experiments.

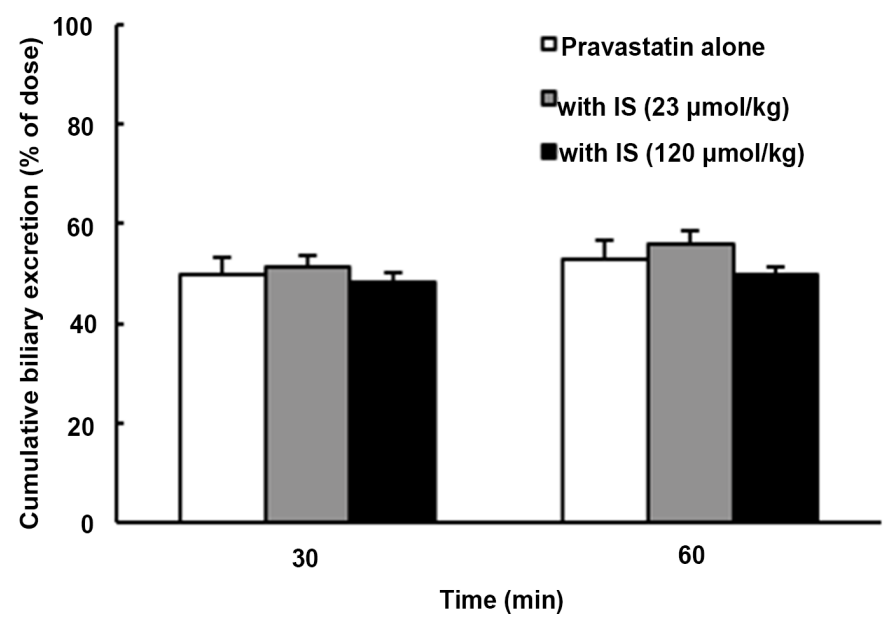

Figure 3. Effects of the intravenous administration of IS on the biliary excretion of pravastatin. Each column represents the mean with S.D. of 3 to 4 experiments.

the bile in an unchanged form within $30 \mathrm{~min}$, and the value remained almost the same after $60 \mathrm{~min}$. The manner of biliary excretion was not altered at all in the presence of IS (Figure 3). 


\section{Discussion}

The results of this study showed that intravenously administered pravastatin disappeared very quickly from the plasma in normal rats (Figure 2) and that more than $50 \%$ of the pravastatin was excreted in the bile within first $60 \mathrm{~min}$ post-administration (Figure 3 ). Moreover, the biliary excretion of pravastatin ended when it had almost completely disappeared from the plasma. These results strongly suggested that pravastatin was taken up very efficiently from the sinusoid into hepatocytes and then transported into the bile across the canalicular membranes.

Typically, three members of the OATP family (OATP1B1, OATP1B3, and OATP2B1) are present on the sinusoidal membrane of human hepatocytes, and pravastatin is known to be a substrate of these three OATPs [19] [20]. It is, therefore, thought that OATPs on the sinusoidal membrane of rat hepatocytes greatly contributed to the hepatic transport of pravastatin. Accordingly, it was expected that, if IS is a capable of potently inhibiting rat OATPs, the rapid disappearance of pravastatin shown in Figure 2 would be delayed with an increase in plasma levels in the presence of IS. However, no elevation in the plasma levels of pravastatin was observed even after IS was administered at dose of 120 $\mu \mathrm{mol} / \mathrm{kg}$ (Figure 2). The dose is very important in this type of study for evaluating the inhibitory effect of a compound on OATP-mediated hepatic transport in vivo. A recent paper pointed out that the IS concentration required for the in vitro inhibition of OATP-mediated transport was greater than clinical IS levels [12]. As IS originates from D-tryptophan in the diet, its plasma levels are dependent on dietary conditions even in patients with seriously impaired renal function. Therefore, in a separate study, we determined the plasma IS levels in Japanese hemodialysis patients living in the Sapporo area and found that, although the number of patients was small, IS levels ranged from 8.9 to $358.4 \mu \mathrm{M}$ with a mean value of $157.9 \mu \mathrm{M}$ [21] [22]. In the present study, after the intravenous administration of IS at a dose of $120 \mu \mathrm{mol} / \mathrm{kg}$, the plasma levels were approximately $600 \mu \mathrm{M}$ at $2 \mathrm{~min}$ and more than $100 \mu \mathrm{M}$ at $120 \mathrm{~min}$. Therefore, we considered that the present results obtained using the intravenous administration of IS at a dose of $120 \mu \mathrm{mol} / \mathrm{kg}$ provide convincing evidence that IS at clinical plasma levels does not influence OATP-mediated pravastatin transport in vivo. In order to further support this conclusion, we elucidated the time course of intravenously administered fluvastatin, which is known to be transported by OATP1B1, OATP1B3 and OATP2B1 [19], at an IS dose of $120 \mu \mathrm{mol} / \mathrm{kg}$. However, IS again failed to induce an elevation in the plasma levels of fluvastatin (data not shown).

Interestingly, pravastatin disappeared from the plasma a little faster in the presence of IS (Figure 2). We reported recently that IS disturbs the binding of pravastatin to albumin [21]. Thus, it was supposed that an increase in the free fraction of pravastatin through its interaction with IS facilitated pravastatin clearance in the plasma. 
Based on previous papers [23] [24], it seems reasonable to consider that the efficient biliary excretion of intravenously administered pravastatin (Figure 3 ) was primarily due to the involvement of rat multidrug resistance-associated protein (Mrp) 2 on the canalicular membrane. Further, our results in this study indicated that, at clinical levels, IS does not exert any modulating effect on Mrp2-mediated the pravastatin transport. We determined the biliary excretion of intravenously administered IS in rats and found that IS appeared only minimally in the bile even after 120 min (unpublished data), indicating that the contribution of Mrp2 to the biliary excretion of IS was rather limited.

To date, several papers have proposed two different mechanisms for the alterations in nonrenal drug clearance induced by uremic toxins including IS; one is the direct inhibition of drug-metabolizing enzymes and/or transporters, and the other is based on the decreased expression of proteins and mRNA due to down-regulation [7] [9] [11] [25]. Our present results give further evidence in contradiction of the first mechanism. Very recently, Katsube et al. [12] demonstrated cooperative inhibitory effects of uremic toxins and some serum components on OATP1B1-mediated transport. It is probable that continuously elevated IS levels in plasma lead to the modulation of OATPs and Mrp2. Therefore, further study is required to develop our knowledge about the effect of IS on the pharmacokinetics of various drugs.

In conclusion, our present results suggest that single intravenous administration of IS to normal rats causes only a very limited modulating effect on the transport mediated by OATPs and Mrp2 present in hepatocytes.

\section{Conflicts of Interest}

We declare no conflict of interest.

\section{References}

[1] Vanholder, R., De Smet, R., Glorieux, G., Argilés, A., Baurmeister, U., Brunet, P., Clark, W., Cohen, G., De Deyn, P.P., Deppisch, R., Descamps-Latscha, B., Henle, T., Jörres, A., Lemke, H.D., Massy, Z.A., Passlick-Deetjen, J., Rodriguez, M., Stegmayr, B., Stenvinkel, P., Tetta, C., Wanner, C. and Zidek, W. (2003) Review on Uremic Toxins: Classification, Concentration, and Interindividual Variability. Kidney International, 63, 1934-1943. https://doi.org/10.1046/j.1523-1755.2003.00924.x

[2] Leong, S.C. and Sirich, T.L. (2016) Indoxyl Sulfate-Review of Toxicity and Therapeutic Strategies. Toxins, 8, 358. https://doi.org/10.3390/toxins8120358

[3] Hung, S.C., Kuo, K.L., Wu, C.C. and Tarng, D.C. (2017) Indoxyl Sulfate: A Novel Cardiovascular Risk Factor in Chronic Kidney Disease. Journal of American Heart Association, 6, e005022. https://doi.org/10.1161/JAHA.116.005022

[4] Taki, K., Nakamura, S., Miglinas, M., Enomoto, A. and Niwa, T. (2006) Accumulation of Indoxyl Sulfate in OAT1/3-Positive Tubular Cells in Kidneys of Patients with Chronic Renal Failure. Journal of Renal Nutrition, 16, 199-203. https://doi.org/10.1053/j.jrn.2006.04.020

[5] Wu, W., Bush, K.T. and Nigam, S.K. (2017) Key Role for the Organic Anion Transporters, OAT1 and OAT3, in the in Vivo Handling of Uremic Toxins. Science Re- 
port, 7, Article No. 4939. https://doi.org/10.1038/s41598-017-04949-2

[6] Tsutsumi, Y., Deguchi, T., Takano, M., Takadate, A., Lindup, W.E. and Otagiri, M. (2002) Renal Disposition of a Furan Dicarboxylic Acid and Other Uremic Toxins in the Rat. Journal of Pharmacology and Experimental Therapeutics, 303, 880-887. https://doi.org/10.1124/jpet.303.2.880

[7] Nolin, T.D. (2008) Altered Nonrenal Drug Clearance on ESRD. Current Opinion in Nephrology and Hypertension, 17, 555-559. https://doi.org/10.1097/MNH.0b013e3283136732

[8] Joy, M.S., Frye, R.F., Nolin, T., Roberts, B.V., La, M.K., Wang, J., Brouwer, K.L.R., Dooley, M.A. and Falk, R.J. (2014) In Vivo Alteration in Drug Metabolism and Transport Pathways in Patients with Chronic Kidney Diseases. Pharmacotherapy, 34, 114-122. https://doi.org/10.1002/phar.1347

[9] Yeung, C.K., Shen, D.D., Thummel, K.E. and Himmelfarb, J. (2014) Effects of Chronic Kidney Disease and Uremia on Hepatic Drug Metabolism and Transport. Kidney International, 85, 522-528. https://doi.org/10.1038/ki.2013.399

[10] Reyes, M. and Benet, L.Z. (2011) Effects of Uremic Toxins on Transport and Metabolism of Different Biopharmaceutics Drug Disposition Classification System Xenobiotics. Journal of Pharmaceutical Sciences, 100, 3831-3842.

https://doi.org/10.1002/jps.22640

[11] Fujita, K., Sugiura, T., Okumura, H., Umeda, S., Nakamichi, N., Watanabe, Y., Suzuki, H., Sunakawa, Y., Shimada, K., Kawara, K., Sasaki, Y. and Kato, Y. (2014) Direct Inhibition and Down-Regulation by Uremic Plasma Components of Hepatic Uptake Transporter for SN-38, an Active Metabolite of Irinotecan, in Human. Pharmaceutical Research, 31, 204-215. https://doi.org/10.1007/s11095-013-1153-x

[12] Katsube, Y., Tsujimoto, M., Koide, H., Ochiai, M., Hojyo, A., Ogawa, K., Kambara, K., Torii, N., Shima, D., Furukubo, T., Izumi, S., Yamakawa, T., Minegami, T. and Nishiguchi, K. (2017) Cooperative Inhibitory Effects of Uremic Toxins and Other Serum Components on OATP1B1-Mediated Transport of SN-38. Cancer Chemotherapy and Pharmacology, 79, 783-789. https://doi.org/10.1007/s00280-017-3276-y

[13] Sato, T., Yamaguchi, H., Kogawa, T., Abe, T. and Mano, N. (2014) Organic Anion Transporting Polypeptides 1B1 and 1B3 Play an Important Role in Uremic Toxin Handling and Drug-Uremic Toxin Interaction in the Liver. Journal of Pharmacy and Pharmaceutical Sciences, 17, 475-484. https://doi.org/10.18433/J3M89Q

[14] Kalliokoski, A. and Niemi, M. (2009) Impact of OATP Transporters on Pharmacokinetics. British Journal of Pharmacology, 158, 693-705. https://doi.org/10.1111/j.1476-5381.2009.00430.x

[15] Lin, C.J., Chen, H.H., Pan, C.F., Chuang, C.K., Wang, T.J., Sun, F.J. and Wu, C.J. (2011) p-Cresylsulfate and Indoxyl Sulfate Level at Different Stages of Chronic Kidney Disease. Journal of Clinical Laboratory Analysis, 25, 191-197. https://doi.org/10.1002/jcla.20456

[16] Tan, X., Cao, X., Zou, J., Shen, B., Zhang, X., Liu, Z., Lv, W., Teng, J. and Ding, X. (2016) Indozyl Sulfate, a Valuable Marker in Chronic Kidney Disease and Dialysis. Hemodialysis International, 21, 161-167. https://doi.org/10.1111/hdi.12483

[17] Everett, D.W., Chando, T.J., Didonado, G.C., Singhvi, S.M., Pan, H.Y. and Weinstein, S.H. (1991) Biotransformation of Pravastatin Sodium in Humans. Drug Metabolism and Disposition, 19, 740-748.

[18] Deguchi, T., Kusuhara, H., Takadate, A., Endou, H., Otagiri, M. and Sugiyama, Y. (2004) Characterization of Uremic Toxin Transport by Organic Anion Transporters in the Kidney. Kidney International, 65, 162-174. 
https://doi.org/10.1111/j.1523-1755.2004.00354.x

[19] Hua, W.J., Hua, W.X. and Fang, H.J. (2011) The Role of OATP1B1 and BCRP in Pharmacokinetics and DDI of Novel Statins. Cardiovascular Therapeutics, 30, e234-e241. https://doi.org/10.1111/j.1755-5922.2011.00290.x

[20] Kellick, K. (2017) Organic Ion Transporters and Statin Drug Interactions. Current Atherosclerosis Report, 19, 65. https://doi.org/10.1007/s11883-017-0701-y

[21] Ichimuta, Y., Takamatsu, H., Ideuchi, H., Takeda, K. and Saitoh, H. (2015) Plasma Concentrations of Anionic Uremic Toxins in Hemodialysis Patients and Their Effects on Protein Binding of Pravastatin. Yakugaku Zasshi, 135, 821-828.

[22] Ichimuta, Y., Takamatsu, H., Ideuchi, H., Takeda, K. and Saitoh, H. (2016) Correlations between Plasma Levels of Anionic Uremic Toxins and Clinical Parameters in Hemodialysis Patients. Yakugaku Zasshi, 136, 1177-1184.

https://doi.org/10.1248/yakushi.15-00252

[23] Ellis, L.C., Hawksworth, G.M. and Weaver, R.J. (2013) ATP-Dependent Transport of Statins by Human and Rat MRP2/Mrp2. Toxicology and Applied Pharmacology, 269, 187-194. https://doi.org/10.1016/j.taap.2013.03.019

[24] Ieiri, I., Higuchi, S. and Sugiyama, Y. (2009) Genetic Polymorphisms of Uptake (OATP1B1, 1B3) and Efflux (MRP2, BCRP) Transporters: Implications for Inter-Individual Differences in the Pharmacokinetics and Pharmacodynamics of Statins and Other Clinically Relevant Drugs. Expert Opinion on Drug Metabolism and Toxicology, 5, 703-729. https://doi.org/10.1517/17425250902976854

[25] Tsujimoto, M., Hatozaki, D., Shima, D., Yokota, H., Furukubo, T., Izumi, S., Yamakawa, T., Minegaki, T. and Nishiguchi, K. (2012) Influence of Serum in Hemodialysis Patients on the Expression of Intestinal and Hepatic Transporters for the Excretion of Pravastatin. Therapeutic Apheresis and Dialysis, 16, 580-587.

https://doi.org/10.1111/j.1744-9987.2012.01100.x 